\title{
Patterns of Mandibular Fractures and Associated Comorbidities in Peshawar, Khyber Pakhtunkhwa
}

Sahd Rashid ${ }^{1}$, Jawad A. Kundi ${ }^{2}$, Amna Sarfaraz ${ }^{3}$, Asif U. Qureshi ${ }^{4}$, Adnan Khan ${ }^{5}$

1. Oral and Maxillofacial Surgery, Rehman Medical Institute, Peshawar, PAK 2. Oral and Maxillofacial Surgery, Sardar Begum Dental College, Peshawar, PAK 3. Dentistry, Rehman College of Dentistry, Peshawar, PAK 4. Oral and Maxillofacial Surgery, Rehman College of Dentistry, Peshawar, PAK 5. Department of Pediatrics, Rehman Medical Institute, Peshawar, PAK

Corresponding author: Sahd Rashid, sahd_rashid@yahoo.com

\section{Abstract \\ Objectives}

The objective of this study was to assess patterns of mandibular fractures and associated comorbidities in Peshawar, Pakistan.

\section{Methodology}

This multicenter, descriptive, cross-sectional study analyzed patients aged $>15$ years who had been clinically or radiographically diagnosed with mandibular fractures from January to December, 2015. Patients with pathological fractures or bomb-blast injuries were excluded. Data were analyzed using IBM SPSS Statistics for Windows, Version 20.0 (IBM Corp., Armonk, NY).

\section{Results}

The 138 patients diagnosed with mandibular fractures in 2015 included 108 men (78.3\%) and 30 women (21.7\%), with a male preponderance of 3.6:1. Most patients (56\%) were aged 15-25 years, followed by those aged 26-35 years (26\%). The most frequent cause of fractures was road traffic accidents (RTAs; $59.42 \%$ ), followed by falls (18.8\%). RTAs were predominant in men (89\%); whereas, falls were predominant in women (80\%). Fractures due to firearm injuries and interpersonal violence were more frequent in men $(p<0.001)$. In patients with unilateral fractures, the most common fracture site was the parasymphysis (24.6\%) followed by the symphysis (10.1\%). In patients with bilateral fractures, the most common fracture sites were the parasymphysis and condyle (11.6\%), followed by the parasymphysis and angle (8.0\%).

\section{Conclusions}

RTA was the most frequent cause of mandibular fracture and trauma. Mandibular fractures were more

Received 09/19/2019

Review began 09/22/2019

Review ended 09/24/2019

Published 09/25/2019

๑) Copyright 2019

Rashid et al. This is an open access

article distributed under the terms of the Creative Commons Attribution License CC-BY 3.0., which permits unrestricted use, distribution, and reproduction in any medium, provided the original author and source are credited. common in men than women, with most patients aged $15-25$ years. The most common fracture site was the parasymphysis.

Categories: Orthopedics, Epidemiology/Public Health, Dentistry

Keywords: mandible fracture, rta, parasymphysis

\section{Introduction}

The facial area is one of the most common sites of injury [1-2]. The mandible is fractured more frequently than any other facial bone, likely because it is exposed and protruding [1,3]. In addition to functional loss, a mandibular fracture can result in mild to moderate impairment or defect [4].

Mandibular fractures are the most frequent type of fracture in the maxillofacial region [5]. Mandibular fractures may occur alone or together with other facial bone fractures. The predicted ratio of mandible to zygomatic to maxillary bone fractures in patients experiencing maxillofacial injury is 9:4:1 [5].

The mandible is particularly prone to maxillofacial trauma because of its unique shape, mobility, and prominence in the facial skeleton. It is the second most common facial bone experiencing traumatic injuries, accounting for $15.5 \%-59 \%$ of all facial fractures [6]. Patients with a broken lower jaw experience pain, difficulty chewing and talking, and esthetic disfigurement [7]. These injuries are often accompanied by psychological effects, along with significant financial costs [7].

The epidemiology of mandible fractures varies over time and in different countries. The etiology of these fractures is multifactorial, with the type and frequency of fracture dependent on socioeconomic status, culture, technology, demography, and economic factors. 
No recent comprehensive study has assessed the significance of mandibular fracture in South Asian countries. Therefore, this study analyzed patterns of mandibular fractures and associated comorbidities in patients evaluated at departments of maxillofacial surgery at teaching hospitals in Peshawar, Pakistan. Determining the frequency of mandibular fractions and their patterns of occurrence can enhance early diagnosis and treatment, thereby reducing morbidity and mortality associated with these fractures.

\section{Materials And Methods}

The present study was carried out at the departments of oral and maxillofacial surgery of three hospitals in Peshawar, Pakistan: Sardar Begum Dental College and Hospital, Rehman Medical Institute, and Northwest General Hospital. Patients aged $>15$ years presenting at these hospitals with mandibular fractures, including X-rays showing a discontinuity of the mandible, from January to December 2015, were included. Patients with pathological fractures or fractures due to bomb blast injuries were excluded.

Based on the World Health Organization software for sample size determination, the minimum sample size was determined to be 138 patients, with a 95\% confidence level and an 8\% margin of error. Non-probability consecutive sampling technique was used as the sampling method.

Patients were examined clinically and radiographically in the outpatient departments of the three hospitals, and a detailed history was taken.

The study protocol was approved by the Ethical Committee of Gandhara University, Peshawar, and all included patients provided written informed consent. Patient information, including, name, age, and gender were recorded on pre-designed forms. Data were analyzed using IBM SPSS Statistics for Windows, Version 20.0 (IBM Corp., Armonk, NY). Continuous variables were reported as mean and standard deviation and categorical variables as number (percent). Patients were stratified by age, gender, and site of mandibular fracture to determine the etiology of mandibular fractures. The level of significance was set at $\mathrm{P}<0.05$.

\section{Results}

The 138 patients included 108 young men (78.3\%) and 30 young women (21.7\%), resulting in a male-tofemale preponderance of $3.6: 1$. The majority (56\%) were aged $15-25$ years, with $26 \%$ aged $26-35$ years, indicating that young adults are mostly affected by mandibular fractures (Figure 1).

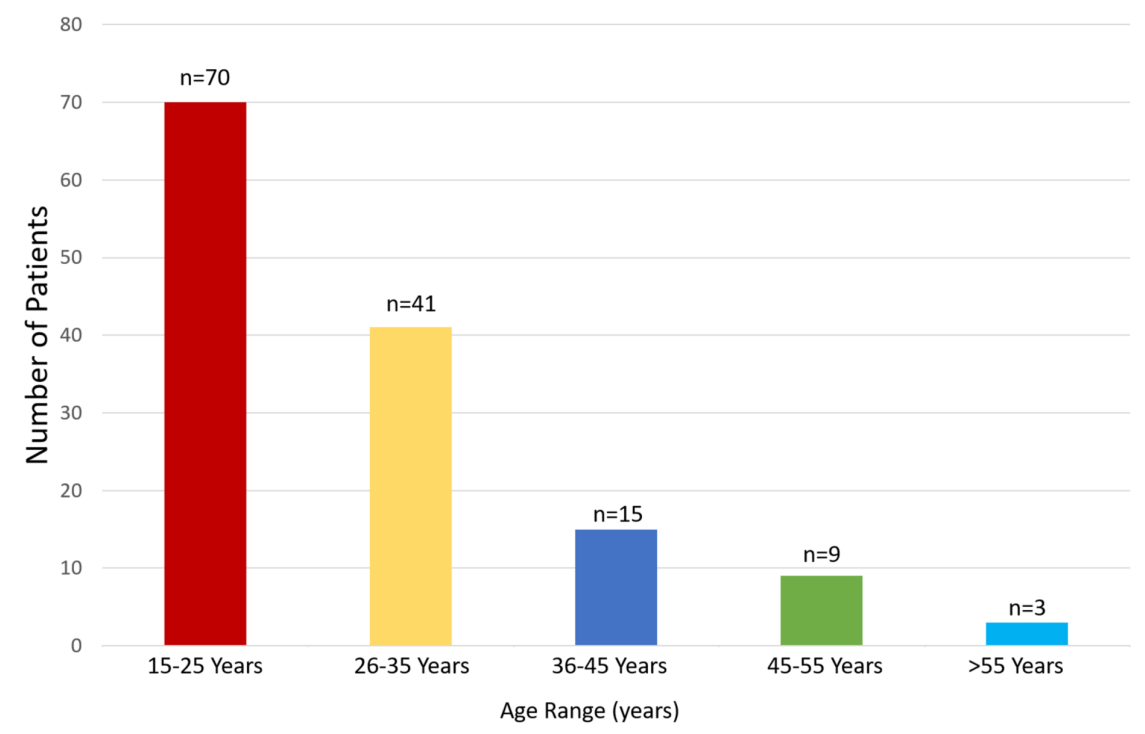

FIGURE 1: Age distribution of patients affected by mandibular fractures $(n=138)$

The most frequent cause of mandibular fracture was road traffic accidents (RTAs; 59.4\%), followed by falls (18.8\%) (Figure 2). RTAs were predominant in men (89\%); whereas, falls were predominant in women (80\%). Fractures due to firearm injuries and interpersonal violence were more frequent in men $(\mathrm{p}<0.001)$. 


\section{Cureus}

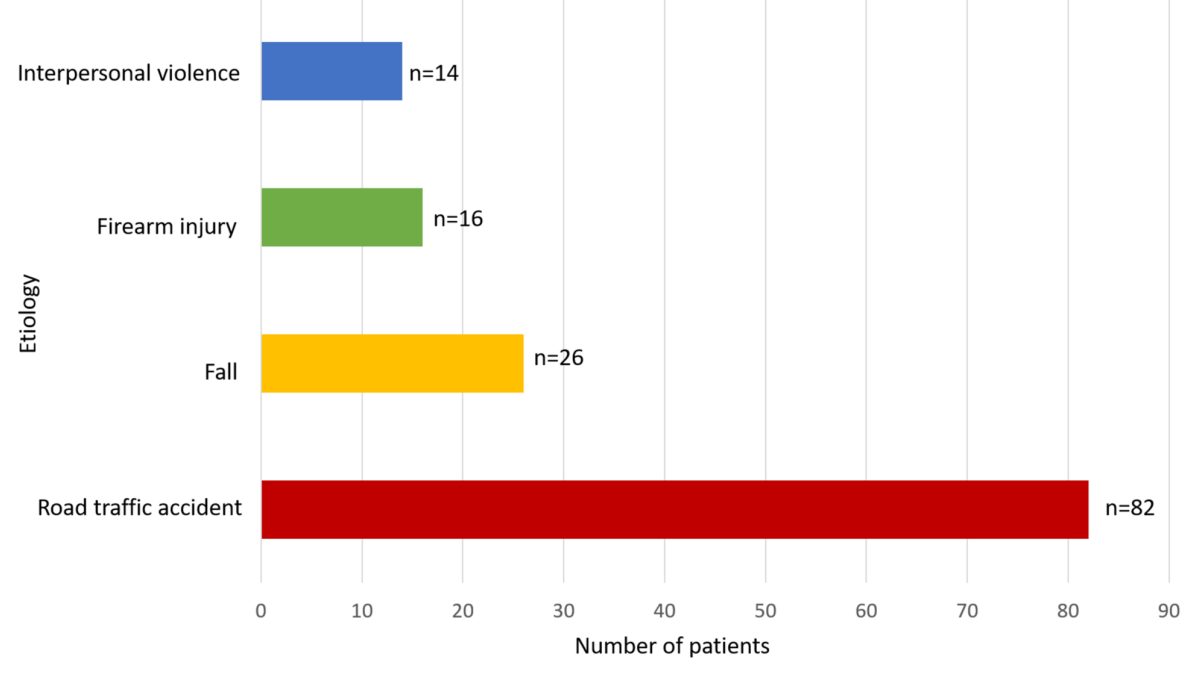

FIGURE 2: Etiology of mandibular fractures $(n=138)$

In patients with unilateral fractures, the most frequent site was the parasymphysis (24.6\%), followed by the symphysis $(10.1 \%)$. Other sites included the condyle ( $8.7 \%)$, body ( $8.7 \%)$, dentoalveolar area (6.5\%), angle (2.2\%), ramus (2.2\%), and comminuted fractures (1.4\%) (Table 1$)$. In patients with bilateral fractures, the most common sites were the parasymphysis and condyle (11.6\%), followed by the parasymphysis and angle (8.0\%), condyle and body (4.3\%), and dentoalveolar area and angle (3.6\%).

\begin{tabular}{|c|c|c|}
\hline Sites & Number & Percentage \\
\hline \multicolumn{3}{|l|}{ Unilateral fractures } \\
\hline Parasymphysis & 34 & $24.63 \%$ \\
\hline Symphysis & 14 & $10.14 \%$ \\
\hline Condyle & 12 & $8.69 \%$ \\
\hline Body & 12 & $8.69 \%$ \\
\hline Dentoalveolar & 9 & $6.52 \%$ \\
\hline Angle & 3 & $2.17 \%$ \\
\hline Ramus & 3 & $2.17 \%$ \\
\hline Comminuted fracture & 2 & $1.44 \%$ \\
\hline \multicolumn{3}{|l|}{ Bilateral fractures } \\
\hline Parasymphysis + condyle & 16 & $11.59 \%$ \\
\hline Parasymphysis + angle & 11 & $7.97 \%$ \\
\hline Condyle + body & 6 & $4.34 \%$ \\
\hline Dentoalveolar + angle & 5 & $3.62 \%$ \\
\hline Body + symphysis & 4 & $2.89 \%$ \\
\hline Condyle + Dentoalveolar & 4 & $2.89 \%$ \\
\hline Left body + Right angle & 2 & $1.44 \%$ \\
\hline Angle + Dentoalveolar + LeFort 2. & 1 & $0.72 \%$ \\
\hline
\end{tabular}

TABLE 1: Distribution of anatomic sites of mandibular fractures $(n=138)$ 


\section{Cureus}

Table 2 shows the associated comorbidities in the study population.

\begin{tabular}{|c|c|c|}
\hline Comorbidities & Number & Percentage \\
\hline \multicolumn{3}{|l|}{ Hard Tissue Injury } \\
\hline LeFort fracture & 35 & $25.36 \%$ \\
\hline Zygomatic fracture & 28 & $20.28 \%$ \\
\hline Fracture of the extremities & 15 & $10.86 \%$ \\
\hline c-spine injury & 15 & $10.86 \%$ \\
\hline Clavicle injury & 15 & $10.86 \%$ \\
\hline TMJ dislocation & 15 & $10.86 \%$ \\
\hline Nasal fracture & 15 & $10.86 \%$ \\
\hline \multicolumn{3}{|l|}{ Soft Tissue Injury } \\
\hline Facial laceration & 62 & $44.92 \%$ \\
\hline Swelling & 35 & $25.36 \%$ \\
\hline Epistaxis & 17 & $12.31 \%$ \\
\hline Ocular injury & 14 & $10.8 \%$ \\
\hline Hyphema + retrobulbar injury & 3 & $2.17 \%$ \\
\hline Infection & 2 & $1.44 \%$ \\
\hline Multiple wounds & 2 & $1.44 \%$ \\
\hline
\end{tabular}

TABLE 2: Comorbidities observed in patients with mandibular fractures $(n=138)$

TMJ: temporomandibular joint.

\section{Discussion}

Epidemiological surveys have shown that the causes, incidence, and patterns of mandibular fracture vary by geographical region, socioeconomic condition, cultural characteristic, and era. In the present study, 56\% of patients with mandibular fracture were aged 15-25 years, consistent with the results of previous studies [89], but differs from that in a Jordanian population [10]. Moreover, mandibular fracture was more common in men than in women, with a $3.6: 1$ ratio, consistent with previous findings $[1,11-12]$. People are more active during the second and third decades of life than during other decades, making them more vulnerable to trauma. Moreover, men participate in more outdoor activities than women.

Previous epidemiological studies have shown that RTA and falls are important causes of mandibular fracture in developing countries [13-14]. In developed countries, however, the leading causes of mandibular fracture are physical assault and interpersonal violence [7]. Seatbelt legislation markedly reduced the incidence of mandibular fracture due to RTA in developed countries, although the incidence was increased by the abuse of alcohol and the use of illicit drugs [15]. The high number of mandibular fractures attributed to RTA in Pakistan is likely due to the lack of seat belt laws, speeding and overloading of vehicles, underage driving, and poor conditions of roads and vehicles. The high incidence of mandibular fractures due to firearm injuries (12\%) was likely due to tribal quarrels and mode of life in the Khyber Pakhtunkhwa (KPK) province, in which the possession of arms is a part of cultural life.

The most common site of mandibular fracture was the parasymphysis (35\%) followed by the symphysis (14\%) and condyle (11\%) [16]. The causes and anatomic sites of mandibular fracture may correlate. For example, the majority of parasymphysis fractures were caused by RTA. The most common soft tissue comorbidity was facial laceration; whereas, the most common hard tissue comorbidity was LeFort fracture. Similar findings were reported by a study in India [17].

An awareness campaign to educate the public, especially drivers, about the importance of restraints and protective measures in motor vehicles should be started. Education of parents about the consequences of falls in children may reduce the incidence of injury in pediatric populations. 


\section{Conclusions}

Most patients who experienced mandibular fractures were young men. The most common etiological factor was RTA, followed by falls, whereas the most frequently fractured site was the parasymphysis. The incidence of RTAs and resultant fractures may be reduced by strict enforcement of seat belt laws, speed limits, and other traffic rules.

\section{Additional Information \\ Disclosures}

Human subjects: Consent was obtained by all participants in this study. Ethical Committee of Gandhara University, Peshawar issued approval 029/6/14. The study protocol was approved by the Ethical Committee of Gandhara University, Peshawar, and all included patients provided written informed consent. Animal subjects: All authors have confirmed that this study did not involve animal subjects or tissue. Conflicts of interest: In compliance with the ICMJE uniform disclosure form, all authors declare the following: Payment/services info: All authors have declared that no financial support was received from any organization for the submitted work. Financial relationships: All authors have declared that they have no financial relationships at present or within the previous three years with any organizations that might have an interest in the submitted work. Other relationships: All authors have declared that there are no other relationships or activities that could appear to have influenced the submitted work.

\section{Acknowledgements}

We are grateful to doctors and staff of Sardar Begum Dental College and Hospital (SBDC), Rehman Medical Institute (RMI) and Northwest General Hospital (NwGH) Peshawar for support and advice.

\section{References}

1. Oberdan W, Finn B: Mandibular fractures in Far North Queensland: an ethnic comparison . ANZ J Surg. 2007, 77:73-79. 10.1111/j.1445-2197.2006.03946.x

2. Bereket C, Şener İ, Şenel E, Özkan N, Yilmaz N: Incidence of mandibular fractures in Black Sea region of Turkey. J Clin Exp Dent. 2015, 7:e410-e413. 10.4317/jced.52169

3. Al-Moraissi EA, Ellis E 3rd: Surgical treatment of adult mandibular condylar fractures provides better outcomes than closed treatment: a systematic review and meta-analysis. J. Oral Maxillofac Surg. 2015, 73:482-493. 10.1016/j.joms.2014.09.027

4. Adhikari R, Karmacharya A, Malla N: Pattern of mandibular fractures in Western Region of Nepal . Nepal J Med Sci. 2012, 1:45-48. 10.3126/njms.v1i1.5798

5. Khan A, Salam A, Khitab U, Khan MT: Pattern of mandibular fractures - a study . Pakistan Oral Dent J. 2009, 29:221-224.

6. Ellis E 3rd, Moos KF, el-Attar A: Ten years of mandibular fractures: an analysis of 2,137 cases . Oral Surg Oral Med Oral Pathol. 1985, 59:120-129. 10.1016/0030-4220(85)90002-7

7. Zix JA, Schaller B, Lieger O, Saulacic N, Thorén H, Iizuka T: Incidence, aetiology and pattern of mandibular fractures in central Switzerland. Swiss Med Wkly. 2011, 141:w13207. 10.4414/smw.2011.13207

8. Down KE, Boot DA, Gorman DF: Maxillofacial and associated injuries in severely traumatized patients: implications of a regional survey. Int J Oral Maxillofac Surg. 1995, 24:409-412. 10.1016/S09015027(05)80469-2

9. Almasri M, Amin D, AboOla AF, Shargawi J: Maxillofacial fractures in Makka City in Saudi Arabia; an 8-year review of practice. Am J Public Health Res. 2015, 3:56-59.

10. Karyouti SM: Maxillofacial injuries at Jordan University Hospital. Int J Oral Maxillofac Surg. 1987, 16:262265. 10.1016/S0901-5027(87)80145-5

11. Ogundare BO, Bonnick A, Bayley N: Pattern of mandibular fractures in an urban major trauma center . J Oral Maxillofac Surg. 2003, 61:713-718. 10.1053/joms.2003.50118

12. Subhashraj K, Ramkumar S, Ravindran C: Pattern of mandibular fractures in Chennai, India . Br J Oral Maxillofac Surg. 2008, 46:126-127. 10.1016/j.bjoms.2006.10.004

13. Sakr K, Farag IA, Zeitoun IM: Review of 509 mandibular fractures treated at the University Hospital, Alexandria, Egypt. Br J Oral Maxillofac Surg. 2006, 44:107-111. 10.1016/j.bjoms.2005.03.014

14. Thorén H, Iizuka T, Hallikainen D, Lindqvist C: Different patterns of mandibular fractures in children. An analysis of 220 fractures in 157 patients. J Craniomaxillofac Surg. 1992, 20:292-296. 10.1016/S10105182(05)80398-1

15. Dongas P, Hall GM: Mandibular fracture patterns in Tasmania, Australia . Aust Dent J. 2002, 47:131-137. 10.1111/j.1834-7819.2002.tb00316.x

16. Ali Z, Punjabi SK, Shafique S, Jan S: Retrospective analysis mandibular fractures at Abbasi Shaheed Hospital, Karachi. Pakistan Oral Dent J. 2015, 31:21-23.

17. Bhattacharya V: Management of soft tissue wounds of the face . Indian J Plast Surg. 2012, 45:436-443. 10.4103/0970-0358.105936 